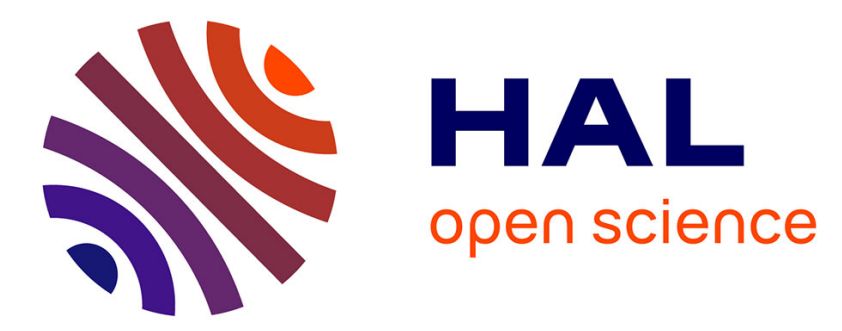

\title{
Investigating the flow dynamics and chemistry of an expanding thermal plasma through $\mathrm{CH}(\mathrm{AX})$ emission spectra
}

\author{
T a R Hansen, J Colsters, M C M van de Sanden, R Engeln
}

\section{- To cite this version:}

T a R Hansen, J Colsters, M C M van de Sanden, R Engeln. Investigating the flow dynamics and chemistry of an expanding thermal plasma through $\mathrm{CH}(\mathrm{AX})$ emission spectra. Journal of Physics D: Applied Physics, 2011, 44 (35), pp.355205. 10.1088/0022-3727/44/35/355205 . hal-00649057

\section{HAL Id: hal-00649057 https://hal.science/hal-00649057}

Submitted on 7 Dec 2011

HAL is a multi-disciplinary open access archive for the deposit and dissemination of scientific research documents, whether they are published or not. The documents may come from teaching and research institutions in France or abroad, or from public or private research centers.
L'archive ouverte pluridisciplinaire HAL, est destinée au dépôt et à la diffusion de documents scientifiques de niveau recherche, publiés ou non, émanant des établissements d'enseignement et de recherche français ou étrangers, des laboratoires publics ou privés. 


\title{
Investigating the flow dynamics and chemistry of an expanding thermal plasma through $\mathrm{CH}(\mathrm{A}-\mathrm{X})$ emission spectra
}

\author{
T A R Hansen, P G J Colsters, M C M van de Sanden and \\ R Engeln \\ Department of Applied Physics, Eindhoven University of Technology, \\ P.O. Box 513, 5600 MB Eindhoven, The Netherlands. \\ E-mail: R.Engeln@tue.nl
}

\begin{abstract}
The gas flow in a linear plasma reactor and the plasma chemistry during hydrogenated amorphous carbon and graphite etching are investigated via time and spatially resolved measurements of the ion density and $\mathrm{CH}$ emission. A convolution of the ion and hydrocarbon density shows the importance of charge transfer in the plasma chemistry which ultimately yields the $\mathrm{CH}$ emission. The spatially resolved measurements clearly visualize the plasma expansion in the reactor and its deflection on a substrate. A stagnation zone is furthermore formed in front of a substrate when placed inside an expanding thermal plasma. An increased ion density further upstream from the substrate is attributed to a reorganisation of the gas recirculation cells in the background of the reactor. The movement of a shutter in and out of the plasma expansion likewise affects these recirculation cells. This movement consequently redirects the energy flow to and from the background, as is deduced from the variation in rotational temperature of the $\mathrm{CH}$ radical.
\end{abstract}


PACS numbers: 52.25.Fi,52.40.Hf,52.70.Kz,52.77.Bn

\section{Introduction}

The next generation experimental fusion reactor, called ITER, is currently under construction in the south of France [1]. Its main purpose is to prove the viability of controlled fusion processes as a power source by achieving a tenfold power multiplication [2]. Such controlled fusion processes require core plasma temperatures on the order of $10 \mathrm{keV}$. Even though temperatures drop significantly by the time the plasma reaches the wall contact points inside the divertor area, wall erosion remains one of the unresolved issues in fusion research. This is particularly the case under the extreme plasma conditions anticipated in ITER. Wall components inside ITER's divertor will face an expected ion and energy flux of up to $10^{24} \mathrm{~m}^{-2} \mathrm{~s}^{-1}$ and 5 to $10 \mathrm{MW} \mathrm{m} \mathrm{m}^{-2}$, respectively, for a duration of $500 \mathrm{~s}$ or longer [2]. How well various materials, such as carbon or tungsten, will withstand such plasma conditions is a topic of active research. In particularly, the ion energy range between thermal temperatures and $10 \mathrm{eV}$ under high flux conditions is largely unexplored [3].

Wall materials for experimental fusion reactors are typically first tested in linear

plasma reactors $[4,5,6,7,8]$. Dedicated plasma reactors provide greater experimental flexibility and can test new materials in anticipation of next generation fusion reactors. Another advantage of linear plasma reactors is the spatial separation between the plasma source and target. This separation allows for high particle fluxes in addition to low plasma temperatures near the substrate. Several reactors dedicated to the study of nuclear materials, such as PSI-I, PSI-II and PISCES, have reached ion fluxes above $10^{22} \mathrm{~m}^{-2} \mathrm{~s}^{-1}[4,5,6]$. To test wall materials in even more extreme conditions, as those expected in ITER, a new facility called Magnum-PSI was recently constructed in The 
Netherlands $[2,9,10,11,1]$. Magnum-PSI uses a cascaded arc as plasma source which is similar in basic design to the source used in this article $[12,13,14]$. Moreover, this source design is used in both research and industry for the removal, deposition or modification of functional materials such as amorphous silicon nitride $\left(a-\mathrm{SiN}_{x}: \mathrm{H}\right)$ and hydrogenated amorphous carbon $(a-\mathrm{C}: \mathrm{H})[15,16,17,18,19,20]$.

The expanding thermal plasma generated by a cascaded arc has been extensively investigated in the past (see section 2). Typical for this type of plasma are the high fluxes (up to $10^{24} \mathrm{~m}^{-2} \mathrm{~s}^{-1}$, depending on the plasma source and reactor configuration) and low electron and ion kinetic temperature $(\sim 1 \mathrm{eV})$ near the arc's nozzle. These temperatures decrease to about $0.1 \mathrm{eV}$ near the target. Furthermore, applying a bias voltage to the target increases the kinetic energy of the incident ions to ITER relevant values $[21,7,2,22]$. These plasma properties — i.e. high ion fluxes and low plasma temperatures — fall in the intersection between typical high-temperature experimental fusion research and low-temperature industrial plasma processing. Based on our experience in low-temperature plasma processing, we can provide insight into the plasma-surface interaction between (relatively) high flux, low-temperature plasmas and $a-\mathrm{C}: \mathrm{H}$ thin film samples as a model for carbon erosion. Surface processes that occur during $a-\mathrm{C}: \mathrm{H}$ erosion under such plasma conditions are largely unexplored and will be treated extensively in a forthcoming paper. Those results will indicate ion-assisted chemical erosion as the dominant erosion process, even at ion kinetic energies around $1-2 \mathrm{eV}[23]$

This article deals with the plasma chemistry during $a$-C:H and graphite erosion, which is dominated by charge transfer between ions and molecular species [24, 25, 26, 27]. Charge transfer (CT), followed by dissociative recombination with an electron (DR), leads to a reduction in ion density as well as molecular fragmentation. The ion density and flux 
towards the surface are important factors in plasma processing. Similar, the resulting molecular fragments can either etch the target or (re-)deposit on it. Furthermore, gas recirculation cells inside a linear plasma reactor play an important role in the chemistry of the entire system $[28,29,30,31,32]$. These recirculation cells lead to a complete mixture of the background gas, while diffusion back and forth between the plasma expansion and background gas connects both regions. The flow dynamics of both ions and molecular species plays a role in where and when molecular fragments are produced and can therefore affect the local plasma chemistry as well as the surface processes. A solid understanding of the gas dynamics and plasma chemistry in a linear plasma reactor is thus important for correctly interpreting experimental results obtained with such a system. Therefore, in addition to the plasma chemistry, this paper will also investigate the flow dynamics. In particular, the effect of a substrate as well as the retraction or extension of a shutter in front of the $a$-C:H sample on the flow dynamics and the local plasma chemistry are investigated.

As can be clearly seen in the photographic images by van Helden et al., a substrate deflects an expanding thermal plasma [33]. The presence of a substrate in a plasma expansion may also lead to changes in the recirculation cells and thus affect where the diffusion of the background gas into the plasma occurs. The influence of a substrate is therefore investigated via spatially resolved measurements of the ion density in an $\mathrm{Ar} / \mathrm{H}_{2}$ plasma, both with and without a substrate. The contours of the expanding thermal plasma and its deflection on the substrate will be visualized with these measurements. The presence of a substrate, moreover, increases the ion density as will be shown. Next, these same plasma conditions are used for the erosion of both $a-\mathrm{C}: \mathrm{H}$ and graphite targets. It will be shown that $\mathrm{CT}$ and $\mathrm{DR}$ between the hydrocarbon etch products of both targets and $\mathrm{Ar}^{+}$ions leads to the formation of ro-vibrationally excited $\mathrm{CH}$ radicals. The optical 
emission of these $\mathrm{CH}$ radicals consequently acts as a tracer for both the argon ions and the hydrocarbon etch products [34]. Spatially resolved measurements of the $\mathrm{CH}$ emission are used to determine the hydrocarbon redistribution near the vicinity of the target. Furthermore the rotational and vibrational temperatures of the $\mathrm{CH}$ radical are strongly affected by the reactor conditions which, in turn, are substantially influenced by the retraction or extension of a shutter in front of the $a-\mathrm{C}: \mathrm{H}$ sample. The changes caused by both the substrate and shutter in either the ion density or the ro-vibrational $\mathrm{CH}$ temperature suggest a reorganisation of the recirculation pattern. Measurements related to the plasma chemistry are thus instrumental in investigating the gas flow and recirculation pattern in a linear plasma reactor.

These issues, i.e. pertubations of the flow dynamics and the local plasma chemistry, should be considered in all linear plasma reactors prior to investigating plasma-surface interactions.

\section{Flow dynamics of an expanding thermal plasma}

Both the flow dynamics of and the plasma chemistry in an expanding thermal plasma have been extensively investigated in the past and are briefly described in this section.

Gas injected under high pressure into a cascaded arc is ionized by a DC current. With a typical ionization degree of around $10 \%$, the generated plasma consists of neutral species as well as ions and electrons. This plasma expands supersonically into the low pressure reactor until it encounters the background gas, at which point a barrel shock is created. After the shock, the plasma continues subsonically towards the substrate or reactor walls. The shock position $z_{s}$ (in $\mathrm{mm}$ ) on the plasma axis can be estimated from:

$$
z_{s}=18 \sqrt{\frac{\Phi}{P_{b g}}} \sqrt[4]{M T}
$$

with the gas flow $\Phi$ in sccs $\left(1 \mathrm{sccs}=2.5 \times 10^{19} \mathrm{~s}^{-1}\right)$, the background pressure $P_{b g}$ in $\mathrm{Pa}$, 
the mass $M$ in amu and the temperature of the plasma source $T$ in $\mathrm{eV}$ [35]. The plasma expansion is furthermore radially symmetric and quasi-neutral $\left(n_{e}=n_{\text {ion }}\right)$, but not in local thermal equilibrium [13].

Four regions have to be considered when discussing the thermal properties of the plasma. First: the electron, ion and neutral gas kinetic temperatures are in equilibrium within the arc itself, which is the only active region in the entire reactor. In other words, the arc produces a thermal plasma with an electron temperature of about $1 \mathrm{eV}$ near the nozzle. Second: due to the low ionization degree, the supersonic part of the expansion behaves similar to that of a hot gas expansion [31]. The ions cool down adiabatically, thereby converting thermal energy into forward directed kinetic energy [13, 36, 37]. The electron kinetic temperature in the supersonic part furthermore decouples from the ion and neutral gas kinetic temperature since the energy exchange between heavy particles occurs more efficiently than between electrons and heavy particles [13]. Third: the temperature increases again across the shock due to the back conversion of forward directed kinetic energy into random thermal energy [30]. Fourth: particle transport in the subsonic part of the plasma expansion, i.e. the region of interest in this paper, is controlled by diffusion [30]. This leads to heat loss at the wall and a subsequent temperature decrease. In this part of the plasma expansion, the electron, ion and neutral gas kinetic temperatures have thermalized and are on the order of $0.1 \mathrm{eV}[36,38]$.

The gas residence time in the reactor can be calculated from the gas flow $\Phi$ (in sccs), the pressure $P$ (in $\mathrm{Pa}$ ) and reactor volume $V\left(\right.$ in $\left.\mathrm{m}^{3}\right)$ with $\tau=\frac{10 \times P V}{\Phi}$ and is on the order of a second during the experiments discussed in this work. Within the expansion itself, however, the ions and electrons have a residence time on the order of $0.1 \mathrm{~ms}$ [28]. The much higher residence time of the background gas causes the background gas to recirculate and interact multiple times with the reactor wall. The resulting recirculation 
cells, wedged between the plasma expansion and the reactor wall, are also responsible for a good mixture of the background gas (figure 1). This gas can moreover diffuse into the plasma over the entire length of the expansion and interact with the electrons and ions emanating from the arc [32]. In the supersonic part of the expansion, background species can enter through the barrel shock if their partial pressure inside the expansion is lower than in the background [31, 32]. This is particularly the case in the region right before the shock front, where the plasma is overexpanded [30]. The total pressure in this so-called zone of silence is lower than the overall background pressure.

\section{Experimental setup}

The cascaded arc, as used in this paper, consists of a stack of four water-cooled copper plates with a central bore of $4 \mathrm{~mm}$ in diameter and has a total length of $24 \mathrm{~mm}$ (figure 1) $[13,14]$. The arc is operated on a $60 \mathrm{~A}$ DC current, a gas flow of 50 sccs argon and a pressure of about 600 mbar. A constant background pressure of $100 \mathrm{~Pa}$ is maintained inside the reactor itself by regulating the opening of the pump valve, i.e. the effective pumping speed. Molecular hydrogen $\left(\mathrm{H}_{2}\right)$ with a gasflow of 1 sccs is moreover injected directly in the background of the reactor via a second gas inlet. The shock position under these conditions is located $\sim 32 \mathrm{~mm}$ from the nozzle, irrespective of the small $\mathrm{H}_{2}$ inflow. An electrically floating substrate is furthermore positioned at $\sim 320 \mathrm{~mm}$ from the nozzle.

This arc configuration is used on two different reactors. Reactor one has an arc and substrate which can move independently with respect to a double Langmuir probe and each other. This double probe measures the ion density with a spatial resolution of $5 \mathrm{~mm}$ in both radial and axial direction. Length and diameter of the tungsten wires are $3.85 \pm 0.05 \mathrm{~mm}$ and $0.85 \pm 0.05 \mathrm{~mm}$, respectively. Spacing between the wires is likewise 
$0.85 \pm 0.05 \mathrm{~mm}$. A Keithley 2400 source meter provides a voltage sweep from $-5 \mathrm{~V}$ to $5 \mathrm{~V}$ in steps of $0.025 \mathrm{~V}$ and measures the current. The resulting I-V characteristic, averaged over 5 voltage sweeps, is analysed according to the theory by Peterson and Albot [39].

Reactor two has an arc and substrate with a fixed position (Fig 11). The substrate temperature is set to a starting value of $250^{\circ} \mathrm{C}$, which increases further due to plasma heating. Two types of carbon-based targets are exposed in this reactor to an Ar plasma, admixed with 1 sccs of $\mathrm{H}_{2}$. Hydrogenated amorphous carbon samples $(a-\mathrm{C}: \mathrm{H})$ are the first type of target. These samples are pre-deposited in-house by means of plasmaenhanced chemical vapour deposition [40, 41]. During deposition, the arc current is $75 \mathrm{~A}$ with an argon gas flow of 100 sccs. The substrate temperature and background pressure during sample preparation are $250^{\circ} \mathrm{C}$ and $31 \mathrm{~Pa}$, respectively. The deposited samples are about $1 \mu \mathrm{m}$ thick. After deposition, the samples are stored in a desiccator. For more details on the deposition process itself, see [42] and references therein. The second type of target is a commercially available fine-grain graphite block (FGG; R6650, SGL Carbon group) with a diameter of $30 \mathrm{~mm}$. This is $45 \mathrm{~mm}$ smaller than the target holder itself, i.e. the substrate.

The erosion process of the carbon targets is monitored by residual gas analysis (RGA; Pfeiffer Vacuum QMS 200) and by optical emission spectroscopy (OES) [43]. Light from the plasma is collected during OES measurements by a lens (focal length $=5.7 \pm$ $0.2 \mathrm{~cm}$ ) and focused onto an optical fiber and transported to a commercially available spectrometer (AvaSpec-2048-4-DT, Avantes), resulting in a line-of-sight measurement. The wavelength resolution of the overview channel $(150-1300 \mathrm{~nm})$ is $1.3 \mathrm{~nm}$ and $0.3 \mathrm{~nm}$ for the high resolution channel $(350-610 \mathrm{~nm})$. The time resolution is 1 and $2.5 \mathrm{~s}$ during the plasma etching of $a-\mathrm{C}: \mathrm{H}$ and FGG, respectively. Of all the different carbonbased molecules present in our reactor, only the emission of $\mathrm{CH}$ and $\mathrm{C}_{2}$ falls within the 
wavelength range of our spectrometer as can be seen in figure 2. Moreover, the rotational $\left(T_{\text {rot }}\right)$ and vibrational $\left(T_{v i b}\right)$ temperature of the electronic $\mathrm{CH}(\mathrm{A}-\mathrm{X})$ transition can be determined by means of the spectrum simulation program LIFBASE [44, 45]. Figure 3, as an illustration, shows a measured $\mathrm{CH}$ spectrum together with the corresponding fit. Rather than fitting all the spectra manually, the method as explained in appendix Appendix $\mathrm{B}$ is used to determine the rotational and vibrational temperature of each spectrum.

\section{Experimental results}

The experimental results are divided into four sections. The first section discusses the ion composition and effective ion mass of the plasma. Section (4.2) deals with the influence of a substrate on the ion density in an $\mathrm{Ar} / \mathrm{H}_{2}$ plasma. The (re)distribution and dissociation of hydrocarbon etch products is discussed in section 4.3. A connection between the ro-vibrational temperatures of the $\mathrm{CH}$ radical and the gas kinetic temperature will be show in the last section, i.e. 4.4 .

\subsection{Ion composition of the plasma}

The ion composition and plasma chemistry in pure argon and argon/hydrogen expanding thermal plasmas have been studied in the past by our group and is therefore not extensively treated here $[13,14,46,37,47,48]$. These studies showed that ionization or dissociation of neutral species via electron impact only occurs in the arc, where the electron temperature and density are high enough. Nevertheless, charge transfer and dissociative recombination within either the arc or the reactor likewise leads to the formation of new species. Reaction rates for charge transfer are overall lower than for dissociative recombination by 2 or 3 orders of magnitude. Charge transfer is thus the 
time-limiting factor in this process. $\mathrm{H}_{2}$ dissociation and ion formation via $\mathrm{CT}$ and $\mathrm{DR}$ in $\mathrm{Ar} / \mathrm{H}_{2}$ plasma is explained in appendix Appendix A.

The effective ion mass is a required input parameter in the analysis of the double Langmuir probe data when using the Peterson and Albot theory. This is $40 \mathrm{amu}$ for $\mathrm{Ar}^{+}$ in a pure argon plasma. The ion composition in an $\mathrm{Ar} / \mathrm{H}_{2}$ plasma consists of $\mathrm{Ar}^{+}, \mathrm{ArH}^{+}$ and $\mathrm{H}_{3}^{+}$and depends strongly on the gas mixture as discussed in appendix Appendix A. The exact ion composition and thus the effective ion mass for the plasma conditions in this work remains however unclear. An ion mass of $40 \mathrm{amu}$ is therefore used as well for the $\mathrm{Ar} / \mathrm{H}_{2}$ measurements in section 4.2, although this approach yields on overestimation of the ion density by up to a factor of four.

\subsection{Influence of a substrate on the plasma expansion}

Figure 4 shows the spatial distribution of the ion density for three different plasma systems with a spatial resolution of $5 \mathrm{~mm}$ in both radial (r) and axial (z) direction. The shock position of the plasma falls outside the measured range. Figures 4.a and 4.b show a pure argon plasma and an $\mathrm{Ar} / \mathrm{H}_{2}$ plasma, respectively, without a substrate. Notice that the scale in figure 4.b (and figure 4.c as well) is nearly one order of magnitude lower than in figure 4.a. This loss in $\mathrm{Ar}^{+}$ions is due to an inflow of $\mathrm{H}_{2}$ from the background which leads to atomic H production via CT and DR (Appendix A). These spatially resolved measurements moreover show that the decrease in radical direction is stronger for larger z-positions. When ions are consumed at any given radial position, they are obviously no longer available further downstream for additional $\mathrm{H}_{2}$ dissociation reactions. Downstream, $\mathrm{H}_{2}$ will thus have to advance further towards the center before undergoing dissociation.

Figure 4.c shows the influence of a substrate on the ion density in an $\mathrm{Ar} / \mathrm{H}_{2}$ plasma. Immediately noticeable is that the highest densities $\left(>3.8 \times 10^{18} \mathrm{~m}^{-3}\right)$ extend further 
into the reactor, towards the substrate. The density at $40 \mathrm{~mm}$ is about $50 \%$ higher when the substrate interacts with the plasma expansion. The last two to three data points in front of the substrate, on the other hand, show a relatively larger decline in density. Notice furthermore the appearance of indentations and protuberances on the plasma boundary and the deflection of the plasma on the substrate. The influence of a substrate on the ion density is further discussed in section 5 .

\subsection{Spatial and time resolved $\mathrm{CH}$ emission during carbon erosion}

A similar $\mathrm{Ar} / \mathrm{H}_{2}$ plasma as shown in figure 4.b and figure 4.c is now used for the erosion of both graphite and $a$-C:H targets. Stable hydrocarbon species detected by RGA during plasma exposure of these two different targets are mainly $\mathrm{CH}_{4}$ and $\mathrm{C}_{2} \mathrm{H}_{y}$ $(y=2,4)$. Previous work in our group has shown that CT and DR with hydrocarbon deposition precursors leads to the formation of excited $\mathrm{CH}$ radicals [27]. Figure 5 shows the relative intensity of the $\mathrm{Q}(0,0)$ band head of $\mathrm{CH}(\mathrm{A}-\mathrm{X})$ transition at $431 \mathrm{~nm}$ with a spatial resolution of $5 \mathrm{~mm}$. The scale on the axis is limited by the size of the viewport and, therefore, smaller than in figure 4. As can be seen in figure 5, $\mathrm{CH}$ radicals are likewise found throughout the reactor during carbon erosion (fine-grain graphite or FGG in this case). With a thermal velocity of $\sim 1 \mathrm{~km} \mathrm{~s}^{-1}$ and a lifetime of 500 to $700 \mathrm{~ns}$ for the first excited state, the $\mathrm{CH}$ radical can travel up to $0.77 \mathrm{~mm}$ before it decays [45]. This short travel distance excludes the carbon surface as the origin of these excited radicals. Electron ionisation of existing $\mathrm{CH}$ radicals in the gas phase is likewise excluded due to the low electron temperature of the plasma. $\mathrm{CH}$ emission thus occurs in the immediate vicinity of its production, i.e. through $\mathrm{CT}$ and DR reactions between $\mathrm{Ar}^{+}$and hydrocarbons such as $\mathrm{CH}_{4}$ or $\mathrm{C}_{2} \mathrm{H}_{2}$.

A mean free path (mfp) for these hydrocarbon etch products is estimated from their thermal velocity, the reaction rate for $\mathrm{CT}$ and the ion density. The thermal velocity is 
around $1 \mathrm{~km} \mathrm{~s}^{-1}$, while the reaction rate is on the order of $10^{-16}$ to $10^{-15} \mathrm{~m}^{3} \mathrm{~s}^{-1}$ for $\mathrm{C}_{1,2} \mathrm{H}_{y}[49,50]$. Acetylene, for instance, would have a mfp on the order of $10-30 \mathrm{~cm}$ in a pure argon plasma with an ion density of $\sim 2 \times 10^{19} \mathrm{~m}^{-3}$ (figure 4.a) $[25,50]$. Figure 4.c in turn yields a much lower ion density of $1-5 \times 10^{18} \mathrm{~m}^{-3}$ for an $\mathrm{Ar} / \mathrm{H}_{2}$ plasma. This translates into a mfp for $\mathrm{CH}_{4}$ and $\mathrm{C}_{2} \mathrm{H}_{2}$ on the order of $20-100 \mathrm{~cm}$ and $50-150 \mathrm{~cm}$, respectively. Although uncertainties in ion density measured via electrical probes can be large, the ion density in our case is more likely overestimated (due to the uncertainty in the ion mass) than underestimated. This implies that the calculated mfp itself is underestimated. Regardless, the mean free path of the hydrocarbons when only considering the charge transfer reaction — is sufficiently large to fill up the entire reactor $(500 \mathrm{~mm}$ in length, $400 \mathrm{~mm}$ in diameter) with etch products from the carbon surface. Likely candidates for the $\mathrm{CH}$ parent molecule therefore include these etch products, although hydrocarbon products of secondary chemical reactions in the background are not entirely excluded.

Six additional observations are made from figure 5:

(i) The highest intensities are measured within the first $10 \mathrm{~mm}$ 's right in front of the fine-grain graphite (FGG) target from where the hydrocarbons originate.

(ii) The e-folding length of the measured intensity on the z-axis is $6.0 \pm 0.5 \mathrm{~mm}$, which is significantly smaller than the previously calculated mean free path of up to $100 \mathrm{~cm}$ for methane. Similar measurements conducted by Westerhout et al. in a pure hydrogen plasma showed a good correspondence between the e-folding length in the $\mathrm{z}$-direction of the $\mathrm{CH}$ emission and the mean free path of methane, injected via the substrate [34]. The neutral density in our case is however one order of magnitude higher, which increases the number of neutral - neutral collisions. This reduces the effective travel distance of the etch products prior to CT and DR and is 
thus expected to yield a smaller e-folding length.

(iii) Emission levels are lower at the edges of the FGG target, i.e. at a radial position of about $\pm 20 \mathrm{~mm}$, compared to the immediate surroundings. This indicates that the region around the sides of the $4 \mathrm{~mm}$ thick target is poor in either $\mathrm{Ar}^{+}$ions or hydrocarbons.

(iv) The pump duct located at the bottom of the back flange, i.e. below the target, is responsible for the asymmetry in the measured intensity at larger radial positions $(>40 \mathrm{~mm})$.

(v) The $\mathrm{CH}$ emission accentuates the central axis of the plasma expansion for $\mathrm{z}$ $>10 \mathrm{~mm}$ 's. It also shows the deflection of the plasma expansion by the substrate.

(vi) The spectrum at each location was measured several times during the measurement, which lasted over an hour. Nevertheless, the variation in intensity is less than $3 \%$.

The (re-)distribution of hydrocarbons in the ground state, which can not be detected via optical emission spectroscopy, is furthermore determined via numerical simulations of the gas flow in the reactor. The DS2V code developed by G.A. Bird is a direct simulation Monte Carlo (DSMC) method and has been previously used to describe the plasma expansion $[51,32,52]$. Our simulation starts from a fully developed expansion of a pure argon gas. After a stable gas flow has been calculated, a secondary gas inlet of methane-like particles is added to the model at the position of the substrate to simulate the erosion of a carbon target. The injected flow ratio of argon to methane is a 100:1. The model contains neither charged particles, nor any gas phase chemistry. The results presented in figure 6 show the gas expansion and its deflection on the substrate. Cooling of the gas along the main axis can likewise be seen. In contrast with the $\mathrm{CH}$ emission, moreover, the injected methane-like particles are primarily found in front of the substrate and in the background of the reactor. The distribution in the $\mathrm{CH}$ emission, 
as measured in figure 5, is thus due to the convolution of the $\mathrm{Ar}^{+}$ion density and the hydrocarbon density throughout the reactor.

A thick FGG target, as used so far, enables steady state measurements. The target type is now switched to $a-\mathrm{C}: \mathrm{H}$ thin films for the study of time dependent effects in the gas flow. Optical emission from the plasma is measured a few mm's in front of an $a-\mathrm{C}: \mathrm{H}$ sample with a time resolution of $1 \mathrm{~s}$. Note that the focus of the optical system in these measurements is located in between sample and shutter (as can be seen in figure 9 later on). This implies that little to none emission of any wavelength is recorded by the spectrometer when the plasma is blocked by the shutter. Figure 7 shows the time evolution of the $\mathrm{CH}$ peak at $431 \mathrm{~nm}$. When the shutter is retracted at $0 \mathrm{~s}$, the measured intensity increases sharply. Afterwards the intensity increases steadily for about $220 \mathrm{~s}$ due to an increased etch rate caused by plasma heating of the substrate. Maximum intensity in the emission is reached a few seconds before the sample is completely eroded as indicated by spectroscopic ellipsometry. Or in other words, $\mathrm{CH}$ emission starts to decrease as the hydrocarbon source (i.e. the $a$-C:H surface) is depleted. Between $\sim 250 \mathrm{~s}$ and $\sim 470$ s, the measured intensity remains high due to a continuous re-deposition and re-erosion and due to the etching of carbon impurities on the reactor walls. Extending the shutter at $\sim 470 \mathrm{~s}$ blocks the plasma expansion again, which strongly reduces the overall light emission at the focal point of the optical measurement system. This verifies that $\mathrm{CH}$ emission is not measured when $\mathrm{Ar}^{+}$ions and electrons are unavailable for $\mathrm{CT}$ and DR at the focal point.

\subsection{Rotational and vibrational temperature of $\mathrm{CH}$}

The method described in section Appendix $\mathrm{B}$ will now be used to determine the rotational and vibrational temperature of the $\mathrm{CH}$ radical for the previously discussed spatial and time resolved measurements. 
4.4.1. Spatially resolved Engeln et al. measured the density of $\mathrm{CH}$ in the ground state during deposition conditions, thereby assuming thermal equilibrium between $\mathrm{CH}$ and the background gas [27]. The rotational temperature in particular was assumed to be a measure of the gas kinetic temperature $\left(T_{\text {gas }}\right)$ [27]. Ro-vibrational temperatures of the first electronically excited state $\mathrm{CH}(\mathrm{A}-\mathrm{X})$, as shown in figure 8 , are on the other hand higher than the gas kinetic temperature of $1000-2000 \mathrm{~K}$. The highest temperatures are measured on the central axis of the plasma expansion and nearest to the cascaded arc. Both $T_{\text {rot }}$ and $T_{v i b}$ decrease in axial direction towards the substrate as well as in radical direction. A similar trend for the gas temperature, seen in the bottom part of figure 6 , indicates a connection between the electronically excited state and $T_{\text {gas }}$ as well. The lifetime of the excited state (section 4.3) however provides insufficient time to equilibrate with the background gas. A memory effect is therefore assumed between the ro-vibrational temperature of the electronically excited $\mathrm{CH}$ and the gas kinetic temperature by proxy of the $\mathrm{CH}$ parent molecule.

4.4.2. Time resolved Figure 9, which corresponds with figure 7, shows the time variation in the rotational and vibrational temperature. The intensity measured after $250 \mathrm{~s}$ is too low to accurately determine these two temperatures. A slow increase from $\sim 4700 \mathrm{~K}$ to $\sim 4800 \mathrm{~K}$ can be observed in figure 9.a. $T_{\text {rot }}$, on the other hand, decreases exponentially from $\sim 3200 \mathrm{~K}$ to $\sim 2200 \mathrm{~K}$. This decrease is explained in detail in section 5. Two spectra - averaged over 10 measurement points and normalized to the $\mathrm{Q}(0,0)$ band head — obtained near the beginning and end of the $a$-C:H erosion experiment are shown in figure 10. A variation in peak intensities relative to the $Q(0,0)$ band head provides visual confirmation of a change in the ro-vibrational $\mathrm{CH}(\mathrm{A}-\mathrm{X})$ temperature (see eq. $2.1 a$ and $2.1 b$ in App. Appendix B). The larger variation in $T_{\text {rot }}$ between beginning and end of the measurement suggests that the rotational energy levels are more sensitive 
to the gas temperature than the vibrational temperature. This can be expected in a low-temperature plasma since the rotational energy spacings $(\sim 0.01 \mathrm{eV})$ are smaller than the vibrational energy spacings $(\sim 0.2 \mathrm{eV})[53]$. 


\section{Discussion and conclusions}

Placing a substrate inside the expanding thermal plasma has a clear effect on the ion density and the shape of the plasma expansion as shown in section 4.2. The lower ion density in front of the substrate is attributed to the formation of a stagnation zone with a thickness on the order of $10 \mathrm{~mm}$ in axial direction. An increased neutral particle (i.e. $\mathrm{H}_{2}$ ) density in this stagnation zone increases the number of ion-neutral collisions via CT and thus also the ion losses. This effect can moreover be seen in the $\mathrm{CH}$ emission, whereby the excited $\mathrm{CH}$ radicals themselves are formed via $\mathrm{CT}$ and $\mathrm{DR}$ between $\mathrm{Ar}^{+}$and hydrocarbon etch products. As stated in section 4.3, the intensity of the $\mathrm{CH}$ emission is due to the convolution of the $\mathrm{Ar}^{+}$ion density and the hydrocarbon density throughout the reactor. An increased pressure in the stagnation zone augments the local hydrocarbon density, which is already high due to the vicinity of the carbon target. The combination of a substrate and a deflected plasma expansion furthermore leads to a restructuring of the recirculation cells in the background. Such a restructuring is moreover considered to be responsible for the reduced decline in ion density further upstream from the substrate. CT reactions outside of the stagnation zone require a molecular gas inflow from the background (or alternatively from the arc, which is not the case here). Previous work in our group showed a bimodal component in the velocity distribution of argon for a pure argon plasma [32]. A hot, fast component originating from the cascaded arc and a slow, cool component from the inflowing background gas. Impeding this gas inflow via a restructured circulatory system in the background thus reduces the ion losses as was observed.

The vibrational and rotational temperature of $\mathrm{CH}$ in section 4.4 likewise provide information about the plasma expansion and indirectly about the recirculation cells. The steady-state measurements, first of all, visualises the plasma cooling in both radial 
and axial direction, thereby relating the rotational and vibrational temperature of $\mathrm{CH}$ to the gas kinetic temperature in the expansion via the $\mathrm{CH}$ parent molecule. The plasma expansion is furthermore deflected by the shutter towards the walls, thereby displacing the recirculation cells (figure 11). The deflected plasma will subsequently heat up both the wall and the background gas. When the shutter is retracted to start the etch process, the walls and the background gas in the reformed recirculation cells no longer receive an energy influx from the plasma and start to gradually cool down. As the background cools down over time, the inflowing gas will likewise have a lower kinetic energy. This temporal variation in the gas kinetic temperature is reflected in the time-dependent rotational temperature of $\mathrm{CH}$, as observed in section 4.4. Or in other words, the rotational temperature of the $\mathrm{CH}$ radical acts as a thermometer for changes in the background environment.

In conclusion, the distribution of electronically excited $\mathrm{CH}$ radicals, locally produced via charge transfer and dissociative recombination reactions, is due to the convolution of the $\mathrm{Ar}^{+}$ion density and the hydrocarbon density throughout the reactor. Moreover, the rotational temperature of electronically excited $\mathrm{CH}$ is related to the gas kinetic temperature via their parent molecules. Variations in the local ion density or gas temperature therefore affect the production of excited species which in turn can have an impact on the local plasma chemistry and surface processes. Both the placement of a substrate and the movement of a shutter inside the plasma expansion are two external influences that cause such variations via a reorganisation of the recirculation cells. The ion density is likewise affected via the formation of a stagnation zone in front of the substrate. Plasma etching of carbon, in particular hydrogenated amorphous carbon, is thus well suited to investigate the local plasma chemistry and identify (externally caused) pertubations in the gas flow of a linear plasma reactor. 
Likewise, the gas flow circulatory system in Magnum-PSI - and ITER, later on should be investigated to account for its effects on the erosion process. Work in that direction has already been started by van Eck et al. and Westerhout et al. [34, 54]. Furthermore, the presence of magnetic fields in both Magnum-PSI and ITER will affect the flow of the plasma. In particular, movement perpendicular to the magnetic field lines will be restricted. A continuation of this paper, therefore, would be an investigation of the gas flow dynamics in a magnetized plasma. Possible research questions include: (a) how and to which extent (external) perturbations to the magnetic field — in analogue of the displacement of a shutter in this paper — affect the gas flow dynamics and (b) what are the consequences thereof on the (local) plasma chemistry and ro-vibrational CH temperatures. In our view, such a study can and should be carried out at the Magnum-PSI and similar facilities to better characterize the reactor in terms of the gas flow dynamics and the influence thereof on erosion studies.

\section{Acknowledgments}

We greatly appreciate the skillful technical assistance of M.J.F. van de Sande, J.J.A. Zeebregts and H.M.M. de Jong. This work is part of the research program of the Dutch Foundation for Fundamental Research on Matter (FOM-TFF). It is also supported by the European Communities under the contract of Association between EURATOM and FOM and carried out within the framework of the European Fusion Programme.

\section{Appendix A. Ion composition of an $\mathrm{Ar} / \mathrm{H}_{2}$ plasma}

Analysis of an IV-characteristic measured by a double Langmuir probe by means of the Peterson and Albot theory requires the ion mass as input parameter [39]. The ion 
composition in an $\mathrm{Ar} / \mathrm{H}_{2}$ plasma is therefore discussed in this appendix.

Charge transfer between $\mathrm{Ar}^{+}$ions and $\mathrm{H}_{2}$ followed by the associated dissociative recombination reactions leads to the production of atomic $\mathrm{H}$ at the expense of the $\mathrm{Ar}^{+}$ ions. This however occurs via $\mathrm{ArH}^{+}$and $\mathrm{H}_{2}^{+}$as intermediate ions as can be seen in the reactions:

$$
\begin{aligned}
\mathrm{Ar}^{+}+\mathrm{H}_{2} & \rightarrow \mathrm{ArH}^{+}+\mathrm{H} \\
& \rightarrow \mathrm{Ar}+\mathrm{H}_{2}^{+},
\end{aligned}
$$

Reactions $(1.1 a)$ and $(1.1 b)$ have a reaction rate of $1.2 \times 10^{-15} \mathrm{~m}^{3} \mathrm{~s}^{-1}$ and $1.7 \times$ $10^{-16} \mathrm{~m}^{3} \mathrm{~s}^{-1}$, respectively [37]. The first reaction is dominant as reaction $(1.1 \mathrm{~b})$ is of little importance below $0.5 \mathrm{eV}[55]$. A third possible CT reaction with a rate of $\sim 10^{-15} \mathrm{~m}^{3} \mathrm{~s}^{-1}$ is given by $[46,48]$ :

$$
\mathrm{H}_{2}^{+}+\mathrm{H}_{2} \rightarrow \mathrm{H}_{3}^{+}+\mathrm{H}
$$

The different DR reactions, not shown here, all have a reaction rate around $\sim$ $10^{-13} \mathrm{~m}^{3} \mathrm{~s}^{-1}$. Reaction (1.2)) thus starts to play a role when the $n_{H_{2}}$ over $n_{e^{-}}$ratio exceeds 100 , as can be seen from the reaction rates.

The ion composition of the plasma, which in turn determines the effective ion mass, is thus to a large degree dependent on the $n_{H_{2}}$ over $n_{e^{-}}$ratio. Even so, the transition between a purely $\mathrm{Ar}^{+}$and a purely $\mathrm{H}_{3}^{+}$ion composition should be smooth. IV-characterics are therefore measured as function of the $\mathrm{H}_{2}$ gas flow admixed to an argon plasma and analysed for a range of ion masses: 3 and 38-41 amu (figure 12). Note that an ion mass of $40 \mathrm{amu}$ is always used for $0 \% \mathrm{H}_{2}$, while a mass of $41 \mathrm{amu}$ represents an ion composition of $100 \% \mathrm{ArH}^{+}$. These measurements were taken in the center of the reactor at a distance of $31.5 \mathrm{~cm}$ from the plasma source, without the presence of a substrate. First of all, the difference in ion density is about 3 to $4 \%$ when 
analysed with a mass of 38 to $41 \mathrm{amu}$. Analysis of the data for a mass of $41 \mathrm{amu}$ yields a density four times higher than for a mass of $3 \mathrm{amu}$. A factor of four difference would thus constitute the worst case scenario, not taking into account any other measurement errors. The graph furthermore shows the strongest decline in ion density between 0 and $2 \%$, regardless of ion mass. Extrapolating this initial decline (for $40 \mathrm{amu}$ ) would yield a 100-fold decrease in ion density for a gas mixture with $\sim 2.2 \% \mathrm{H}_{2}$. The measured ion density for gas mixtures with more than $2 \% \mathrm{H}_{2}$ however remains higher than expected from a linear consumption of $\mathrm{Ar}^{+}$ions. This is attributed to $\mathrm{H}_{3}^{+}$formation, which counteracts the loss of $\mathrm{Ar}^{+}$in the total ion density. Previous work in our group also showed that more than $3 \%$ of $\mathrm{H}_{2}$ in the gas flow leads to a drastic change in the ion composition or in the behaviour of the arc $[47,56]$. A gas mixture of $\sim 2 \%$ of $\mathrm{H}_{2}$, as used in this work, falls within the transition from an $\mathrm{Ar}^{+}$dominated to an $\mathrm{H}_{3}^{+}$dominated plasma.

\section{Appendix B. Fitting $\mathrm{CH}(\mathrm{A}-\mathrm{X})$ spectra}

The spectrum simulation program Lifbase can determine the rotational and vibrational temperature of the electronic $\mathrm{CH}(\mathrm{A}-\mathrm{X})$ transition. Manually fitting each spectrum is however not always feasible when large data sets are involved. Beulens et al. observed that $T_{v i b}$, fortunately, depends heavily on the ratio of the $\mathrm{Q}(0,0)$ and $\mathrm{Q}(2,2)$ band heads, more so than $T_{\text {rot }}[24]$. This allows for a separation between the rotational and vibrational temperatures based on the relative peak intensity. Therefore, the following empirical approach can be used. First, lifbase is used to simulate a set of $\mathrm{CH}(\mathrm{A}-\mathrm{X})$ spectra for a wide range of rotational and vibrational temperatures. Two proportionality factors are then determined from this set:

$$
\mathrm{P}_{\mathrm{vib}}=\frac{\mathrm{Q}(2,2)}{\mathrm{Q}(0,0)}
$$




$$
\mathrm{P}_{\mathrm{rot}}=\frac{\sum_{415 \mathrm{~nm}}^{431 \mathrm{~nm}} \mathrm{R}(\mathrm{i}, \mathrm{f})}{\mathrm{Q}(0,0)}
$$

with $\mathrm{i}$ and $\mathrm{f}$ the initial and final vibrational state, respectively. The $\mathrm{Q}(0,0)$ band head is included in the sum of $(2.1 b)$ as well. The difference in rotational quantum number $(\Delta J)$ is 1 for the P-branch, 0 for the Q-branch and - 1 for the R-branch. Second, two analytic expressions are obtained for these proportionality factors as function of the simulated temperature (figure 13):

$$
\begin{aligned}
& \mathrm{P}_{\mathrm{vib}}=a+b \times \ln \left(\mathrm{T}_{v i b}+c\right) \\
& \mathrm{P}_{\text {rot }}=d \times \mathrm{T}_{\text {rot }}+e,
\end{aligned}
$$

with the inverse relations given by:

$$
\begin{aligned}
& \mathrm{T}_{\text {vib }}=a \times e^{\frac{\mathrm{P}_{\text {vib }}}{b}}+e \\
& \mathrm{~T}_{\text {rot }}=d \times \mathrm{P}_{\mathrm{rot}}+e .
\end{aligned}
$$

Table 1 lists the fit parameters $a$ through $e$ for both sets of equations. The third and last step is to determine the ratios $\mathrm{P}_{\mathrm{vib}}$ and $\mathrm{P}_{\text {rot }}$ for each measured spectrum. Both temperatures are then calculated from these measured ratios. 
[1] Iter homepage.

[2] A. W. Kleyn, W. Koppers, and N. Lopes Cardozo. Plasma-surface interaction in iter. Vacuum, 80:1098, 2006.

[3] J Roth. Status of knowledge of chemical erosion of carbon and critical issues for extrapolation to iter. Phys. Scr., T124:37, 2006.

[4] D.M. Goebel, G. Campbell, and R.W. Conn. Plasma surface interaction experimental facility (pisces) for materials and edge physics studies. J. Nucl. Mater., 121:277, 1984.

[5] M Balden and J Roth. New weight-loss measurements of the chemical erosion yields of carbon materials under hydrogen ion bombardment. J. Nucl. Mater., 280:39, 2000.

[6] P Kornejew, W Bohmeyer, H-D Reiner, and C H Wu. Chemical erosion of cfc at high ion flux densities. Phys. Scr., T91:29, 2001.

[7] J. Roth, R. Preuss, W. Bohmeyer, S. Brezinsek, A. Cambe, E. Casarotto, R. Doerner, E. Gauthier, G. Federici, S. Higashijima, J. Hogan, A. Kallenbach, A. Kirschner, H. Kubo, J. M. Layet, T. Nakano, V. Philipps, A. Pospieszczyk, R. Pugno, R. Ruggieri, B. Schweer, G. Sergienko, and M. Stamp. Flux dependence of carbon chemical erosion by deuterium ions. Nucl. Fusion, 44:L21-L25, 2004.

[8] Dong Xie, Hengjun Liu, Xingrui Deng, Y. X. Leng, and Nan Huang. Deposition of a-c:h films on uhmwpe substrate and its wear-resistance. Appl. Surf. Sci., 256(1):284, 2009.

[9] H. J. N. van Eck, W. R. Koppers, G. J. van Rooij, W. J. Goedheer, R. Engeln, D. C. Schram, N. J. Lopes Cardozo, and A. W. Kleyn. Modeling and experiments on differential pumping in linear plasma generators operating at high gas flows. J. Appl. Phys., 105(6):063307, 2009.

[10] J. Westerhout, W. R. Koppers, W. A. J. Vijvers, R. S. Al, S. Brezinsek, S. Brons, H. J. N. van Eck, R. Engeln, B. de Groot, R. Koch, H. J. van der Meiden, M. P. Nuijten, V. Philipps, M. J. van de Pol, P. R. Prins, U. Samm, J. Scholten, D. C. Schram, B. Schweer, P. H. M. Smeets, D. G. Whyte, E. Zoethout, A. W. Kleyn, W. J. Goedheer, N. J. Lopes Cardozo, and G. J. van Rooij. Psi research in the iter divertor parameter range at the fom psi-lab. Phys. Scr., T128:18, 2007.

[11] N. Holtkamp. The status of the iter design. Fusion Eng. Des., 84(2-6):98, 2009. Proceeding of the 25th Symposium on Fusion Technology - (SOFT-25).

[12] B. de Groot, Z. Ahmad, R. P. Dahiya, R. Engeln, W. J. Goedheer, N. J. Lopes Cardozo, and V. Veremiyenko. Magnum-psi, a new linear plasma generator for plasma-surface interaction 
studies in iter relevant conditions. Fusion Eng. Des., 66-68:413, 2003. 22nd Symposium on Fusion Technology.

[13] G. M. W. Kroesen, D. C. Schram, and J. C. M. de Haas. Description of a flowing cascade arc plasma. Plasma Chem. Plasma Process., 10:531, 1990.

[14] M. C. M. van de Sanden, G. M. Janssen, J. M. de Regt, D. C. Schram, J. A. M. van der Mullen, and B. van der Sijde. A combined thomson-rayleigh scattering diagnostic using an intensified photodiode array. Rev. Sci. Instrum., 63:3369, 1992.

[15] J. W. A. M. Gielen, P. R. M. Kleuskens, M. C. M. van de Sanden, L. J. van Ijzendoorn, D. C. Schram, E. H. A. Dekempeneer, and J. Meneve. Optical and mechanical properties of plasmabeam-deposited amorphous hydrogenated carbon. J. Appl. Phys., 80(10):5986, 1996.

[16] J. Robertson. Diamond-like amorphous carbon. Mater. Sci. Eng., R., 37:129, 2002.

[17] J. Benedikt, R. V. Woen, S. L. M. van Mensfoort, V. Perina, J. Hong, and M. C. M. van de Sanden. Plasma chemistry during the deposition of a-c:h films and its influence on film properties. Diamond Rel. Mater., 12(2):90, 2003. Proceedings of the 4th Specialist Meeting on Amorphous Carbon.

[18] Yu. A. Mankelevich, N. V. Suetin, M. N. R. Ashfold, W. E. Boxford, A. J. Orr-Ewing, J. A. Smith, and J. B. Wills. Chemical kinetics in carbon depositing d.c.-arc jet cvd reactors. Diamond Rel. Mater., 12(3-7):383, Mar-Jul 2003.

[19] B. Hoex, A. J. M. van Erven, R. C. M. Bosch, W. T. M. Stals, M. D. Bijker, P. J. van den Oever, W. M. M. Kessels, and M. C. M. van de Sanden. SHORT COMMUNICATION Industrial highrate $(5 \mathrm{~nm} / \mathrm{s})$ deposited silicon nitride yielding high-quality bulk and surface passivation under optimum anti-reflection coating conditions. Prog. Photovoltaics Res. Appl., 13(8):705-712, 2005.

[20] J. W. Weber. Spectroscopic ellipsometry on hydrocarbon erosion by plasma jets. Master's thesis, Eindhoven University of Technology, Eindhoven, April 2009.

[21] A von Keudell and W Jacob. Growth and erosion of hydrocarbon films investigated by in situ ellipsometry. J. Appl. Phys., 79(2):1092, JAN 151996.

[22] P. Kudlacek, R. F. Rumphorst, and M. C. M. van de Sanden. Accurate control of ion bombardment in remote plasmas using pulse-shaped biasing. J. Appl. Phys., 106(7):073303, 2009.

[23] A. Annen and W. Jacob. Chemical erosion of amorphous hydrogenated boron films. Appl. Phys. Lett., 71:1326, 1997.

[24] J. J. Beulens, C. Gastineau, N. Guerrassimov, J. Koulidiati, and D. C. Schram. Atomic and 
molecular emission spectroscopy on an expanding argon/methane plasma. Plasma Chem. Plasma Process., 14(1):15, 1994.

[25] J. W. A. M. Gielen, M. C. M. van de Sanden, and D. C. Schram. Plasma beam deposited amorphous hydrogenated carbon: Improved film quality at higher growth rate. Appl. Phys. Lett., 69(2):152, 1996.

[26] A. de Graaf, M. F. A. M. van Hest, M. C. M. van de Sanden, K. G. Y. Letourneur, and D. C. Schram. Argon ion-induced dissociation of acetylene in an expanding ar/c2h2 plasma. Appl. Phys. Lett., 74:2927, 1999.

[27] R Engeln, K. G. Y. Letourneur, M. G. H. Boogaarts, M. C. M. van de Sanden, and D. C. Schram. Detection of ch in an expanding argon/acetylene plasma using cavity ring down absorption spectroscopy. Chem. Phys. Lett., 310:405, 1999.

[28] R. F. G. Meulenbroeks, D. C. Schram, M. C. M. van de Sanden, and J. A. M. van der Mullen. Wall association and recirculation in expanding thermal arc plasmas. Phys. Rev. Lett., 76(11):1840, MAR 111996.

[29] R. F. G. Meulenbroeks, R. A. H. Engeln, J. A. M. van der Mullen, and D. C. Schram. Coherent anti-stokes raman scattering performed on expanding thermal arc plasmas. Phys. Rev. E, 53(5):5207-5217, May 1996.

[30] S Mazouffre, M. G. H. Boogaarts, I. S. J. Bakker, P Vankan, R Engeln, and D. C. Schram. Transport of ground-state hydrogen atoms in a plasma expansion. Phys. Rev. E, 64:016411, 2001.

[31] R Engeln, S Mazouffre, P Vankan, D C Schram, and N Sadeghi. Flow dynamics and invasion by background gas of a supersonically expanding thermal plasma. Plasma Sources Sci. Technol., 10(4):595, 2001.

[32] O Gabriel, P G J Colsters, D C Schram, and R Engeln. Two-dimensional flow characteristic of a hot expanding plasma. Plasma Sources Sci. Technol., 17(1):015011, 2008.

[33] J. H. van Helden, R Zijlmans, R Engeln, and D. C. Schram. Molecule formation in $\mathrm{n}$ and o containing plasmas. IEEE Trans. Plasma Sci., 33(2):390, April 2005.

[34] J. Westerhout, N. J. Lopes Cardozo, J. Rapp, and G. J. van Rooij. Ch spectroscopy for carbon chemical erosion analysis in high density low temperature hydrogen plasma. Appl. Phys. Lett., 95(15):151501, October 2009.

[35] P. Vankan, S. Mazouffre, R. Engeln, and D. C. Schram. Inflow and shock formation in supersonic, 
rarefied plasma expansions. Phys. Plasmas, 12(10):102303, 2005.

[36] M. C. M. van de Sanden, J. M. de Regt, and D. C. Schram. Recombination of argon in an expanding plasma-jet. Phys. Rev. E, 47:2792, 1993.

[37] D. K. Otorbaev, A. J. M. Buuron, N. T. Guerrassimov, M. C. M. van de Sanden, and D. C. Schram. Spectroscopic measurement of atomic-hydrogen level populations and hydrogen dissociation degree in expanding cascaded arc plasmas. J. Appl. Phys., 76(8):4499, OCT 151994.

[38] R. F. G. Meulenbroeks, P. A. A. van der Heijden, M. C. M. van de Sanden, and D. C. Schram. Fabry-p[e-acute]rot line shape analysis on an expanding cascaded arc plasma in argon. J. Appl. Phys., 75(6):2775, 1994.

[39] E. W. Peterson and L. Talbot. Collisionless electrostatic single-probe and double-probe measurements. AIAA J., 8:2215, 1970.

[40] J. W. A. M. Gielen, M. C. M. van de Sanden, P. R. M. Kleuskens, and D. C. Schram. Quality improvement of plasma-beam-deposited amorphous hydrogenated carbon with higher growth rate. Plasma Sources Sci. Technol., 5(3):492, 1996.

[41] S. V. Singh, M. Creatore, R. Groenen, K. Van Hege, and M. C. M. van de Sanden. A hard graphite-like hydrogenated amorphous carbon grown at high deposition rate. Appl. Phys. Lett., 92(22):221501, 2008.

[42] J. W. Weber, T. A. R. Hansen, M. C. M. van de Sanden, and R. Engeln. B-spline parametrization of the dielectric function applied to spectroscopic ellipsometry on amorphous carbon. J. Appl. Phys., 106(12):123503, December 2009.

[43] G. Dingemans, M. N. van den Donker, A. Gordijn, W. M. M. Kessels, and M. C. M. van de Sanden. Probing the phase composition of silicon films in situ by etch product detection. Appl. Phys. Lett., 91(16):161902, 2007.

[44] J. Luque and D. R. Crosley. Lifbase: Database and spectral simulation program (version 1.9). In SRI International Report MP 99-009, 1999.

[45] J Luque and D. R. Crosley. Electronic transition moment and rotational transition probabilities in ch .1. a (2)delta-x(2)pi system. J. Chem. Phys., 104:2146, 1996.

[46] M. J. de Graaf, R. Severens, R. P. Dahiya, M. C. M. van de Sanden, and D. C. Schram. Anomalous fast recombination in hydrogen plasmas involving rovibrational excitation. Phys. Rev. E, 48(3):2098, SEP 1993.

[47] R. F. G. Meulenbroeks, R. A. H. Engeln, M. N. A. beurskens, R. M. J. Paffen, M. C. M. van de 
Sanden, J. A. M. van der Mullen, and D. C. Schram. The argon-hydrogen expanding plasma model and experiments. Plasma Sources Sci. Technol., 4(1):74, FEB 1995.

[48] P. Vankan, D. C. Schram, and R. Engeln. High rotational excitation of molecular hydrogen in plasmas. Chem. Phys. Lett., 400(1-3):196, 2004.

[49] Ariel de Graaf. Deposition of CNH Materials: Plasma and Film Characterization. PhD thesis, Eindhoven University of Technology, Eindhoven, 2000.

[50] J. Benedikt, D. C. Schram, and M. C. M. van de Sanden. Detailed tims study of ar/c2h2 expanding thermal plasma: Identification of a-c:h film growth precursors. J. Phys. Chem. A, 109(44):10153, 102005.

[51] S. E. Selezneva, M. I. Boulos, M. C. M. van de Sanden, R. Engeln, and D. C. Schram. Stationary supersonic plasma expansion: continuum fluid mechanics versus direct simulation monte carlo method. J. Phys. D: Appl. Phys., 35(12):1362, JUN 212002.

[52] G. Abbate, B. J. Thijsse, and C. R. Kleijn. Multi-scale Modelling of the Two-Dimensional Flow Dynamics in a Stationary Supersonic Hot Gas Expansion. Computational Science-ICCS 2008, 5102:251, 2008.

[53] M. A. Lieberman and A. J. Lichtenberg. Principles of Plasma Discharges and Materials Processing. John Wiley \& Sons, Inc., Hoboken, New Jersey, $2^{\text {nd }}$ ed. edition, 2005.

[54] H J N van Eck, T A R Hansen, A W Kleyn, H J van der Meiden, D C Schram, and P A Zeijlmans van Emmichoven. A differentially pumped argon plasma in the linear plasma generator magnumpsi: gas flow and dynamics of the ionized fraction. Plasma Sources Science and Technology, 20(4):045016, 2011.

[55] R. F. G. Meulenbroeks, A. J. van Beek, A. J. G. van Helvoort, M. C. M. van de Sanden, and D. C. Schram. Argon-hydrogen plasma-jet investigated by active and passive spectroscopic means. Phys. Rev. E, 49(5):4397, MAY 1994.

[56] W. M. M. Kessels, C. M. Leewis, M. C. M. van de Sanden, and D. C. Schram. Formation of cationic silicon clusters in a remote silane plasma and their contribution to hydrogenated amorphous silicon film growth. J. Appl. Phys., 86(7):4029, 1999.

\section{Figures and Tables}




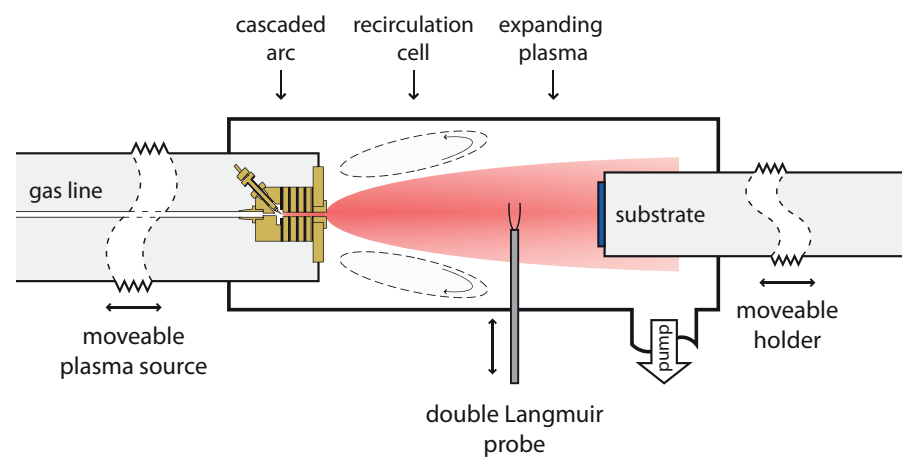

Figure 1: (Colour online) Schematic cross-section of the reactor with movable plasma source and substrate. Recirculation cells are responsible for a complete mixture of the background gas.

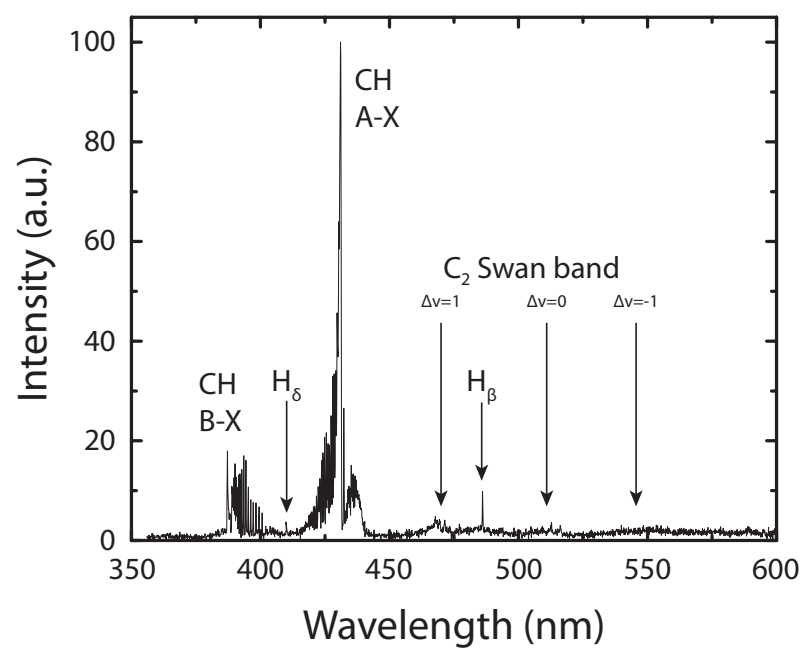

Figure 2: Optical emission spectrum of an $\mathrm{Ar} / \mathrm{H}_{2}$ plasma during $a-\mathrm{C}: \mathrm{H}$ etching. $\mathrm{CH}, \mathrm{C}_{2}$ and two of the $\mathrm{H}$ Balmer $\left(\mathrm{H}_{\beta}, \mathrm{H}_{\delta}\right)$ lines are clearly visible. 


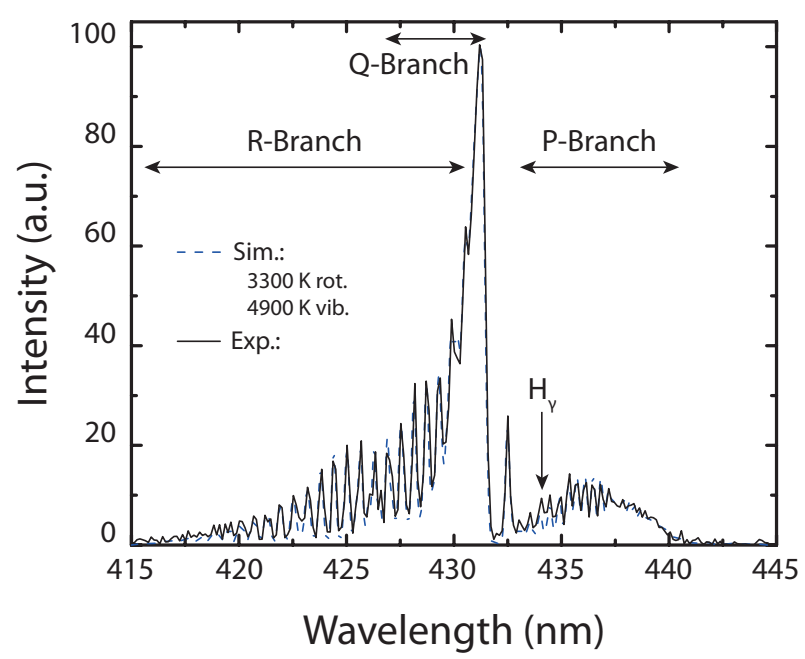

Figure 3: (Colour online) Measured and fitted spectrum of a typical $\mathrm{CH}(\mathrm{A}-\mathrm{X})$ spectrum. Rotational and vibrational temperatures in this example are 3300 and $4900 \mathrm{~K}$, respectively. The $\mathrm{P}(\Delta J=1), \mathrm{Q}(\Delta J=0)$ and $\mathrm{R}(\Delta J=-1)$ branches as well as $\mathrm{H}_{\gamma}$ are indicated in the graph. 


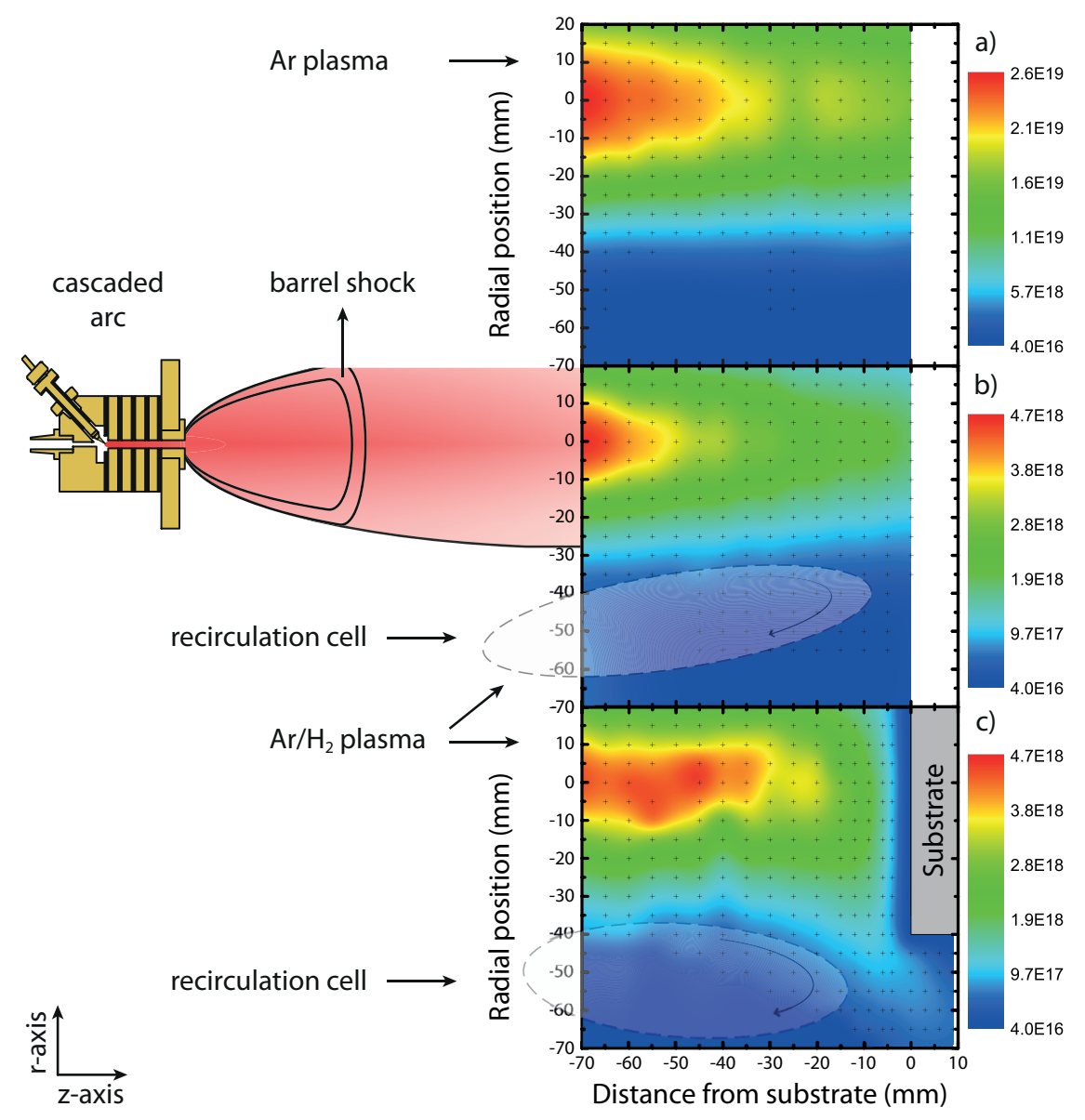

Figure 4: (Colour online) Cross-section of the ion density (in $\mathrm{m}^{-3}$ ) for a) a pure argon plasma, b) an argon plasma admixed with $2 \% \mathrm{H}_{2}$ and the same $\mathrm{Ar} / \mathrm{H}_{2}$ plasma c) with a substrate at floating potential. Note the difference in scale between frame $a$ and frames $b$ and $\mathrm{c}$. 


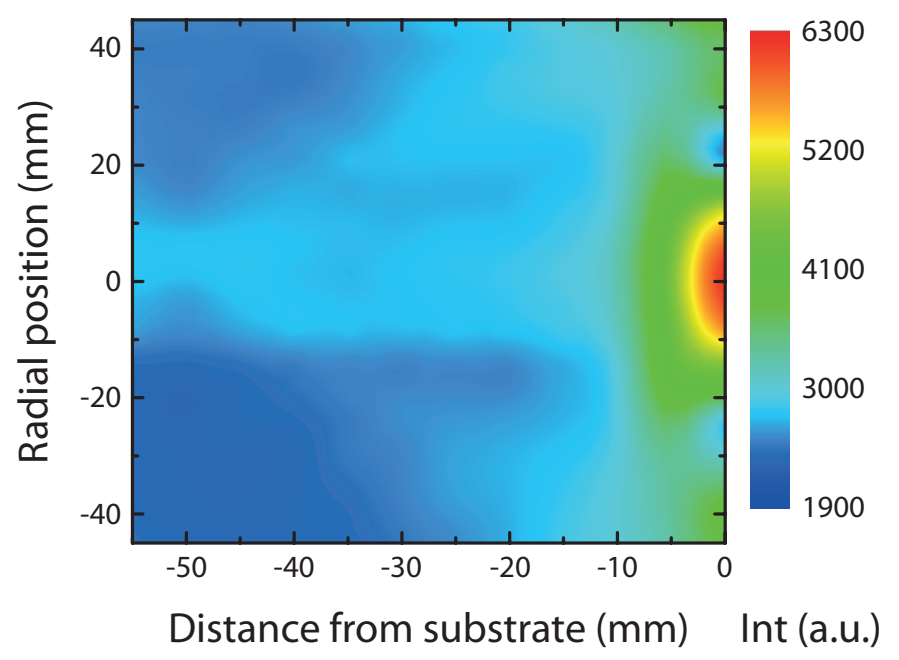

Figure 5: (Colour online) Spatially resolved line-of-sight measurements of the $\mathrm{CH}(\mathrm{A}-\mathrm{X})$ band emission visualize the plasma expansion. The highest emission can be found right in front of the carbon target.

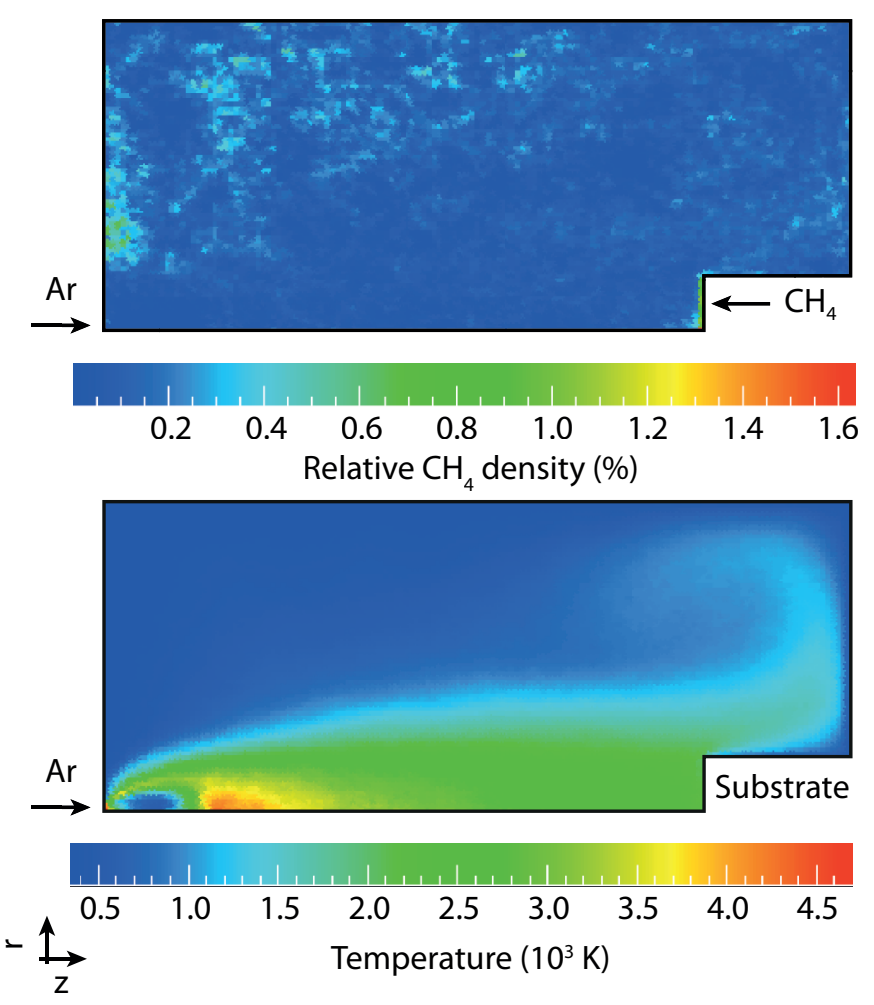

Figure 6: (Colour online) Numerical simulation of the plasma expansion. Top image shows the distribution in the reactor of a methane-like gas, injected at the substrate. Bottom image shows the temperature in the reactor. The expansion and its deflection on the substrate are clearly visible. 


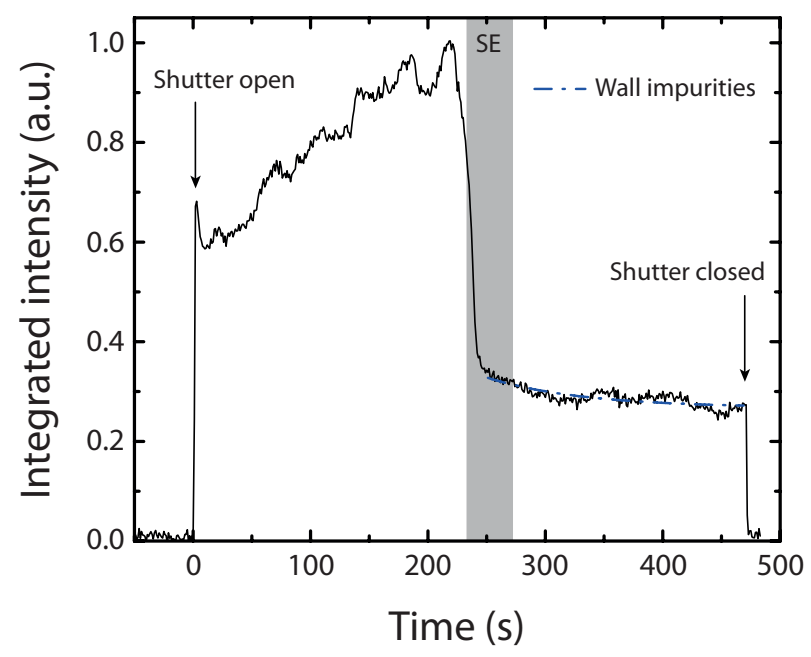

Figure 7: Evolution of the $\mathrm{CH}(\mathrm{A}-\mathrm{X})$ emission a few mm's in front of an $a$-C:H sample. The time resolution is $1 \mathrm{~s}$. The gray bar indicates the uncertainty in when the sample is completely eroded according to spectroscopic ellipsometry. The elevated emission after $250 \mathrm{~s}$ is due to wall impurities.

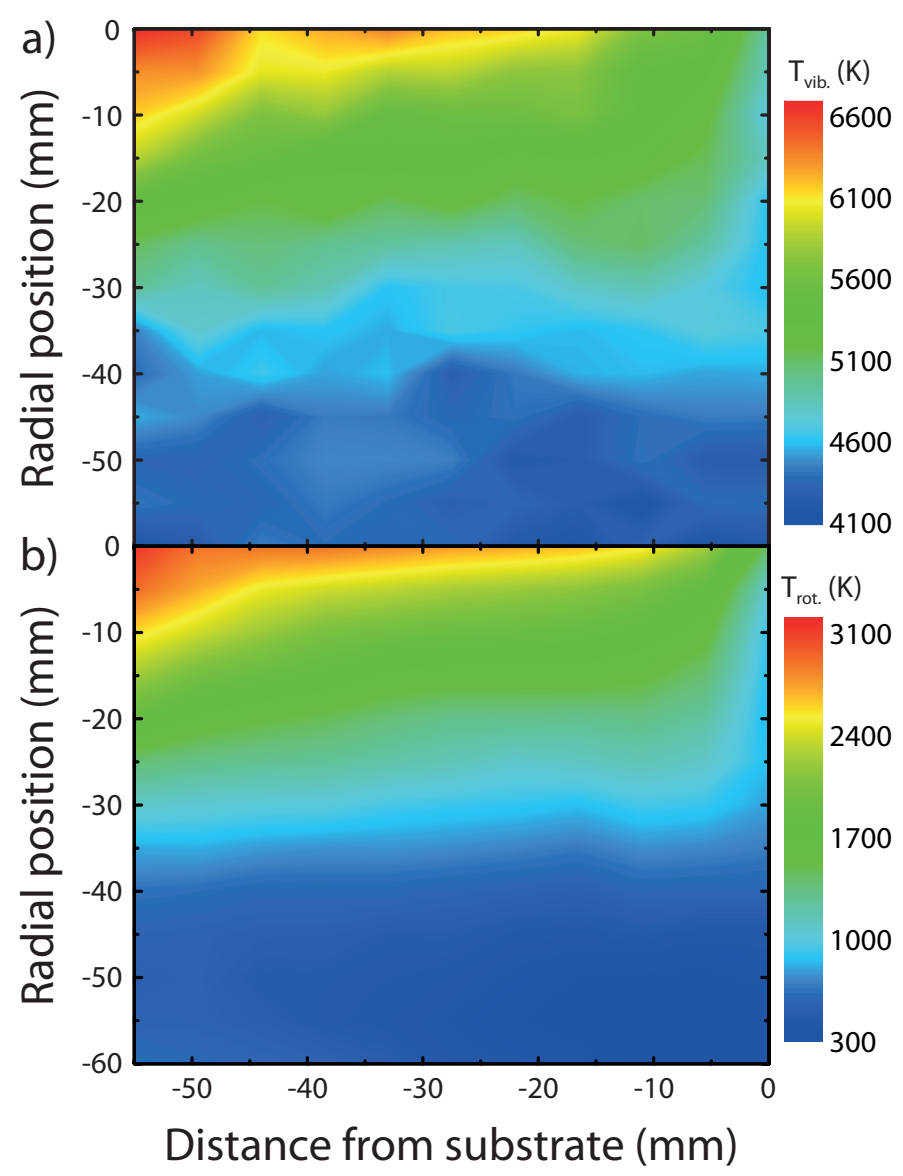

Figure 8: (Colour online) Spatially resolved a) vibrational and b) rotational temperature of $\mathrm{CH}(\mathrm{A}-\mathrm{X})$ during plasma erosion of a FGG target. See also figure 5. 


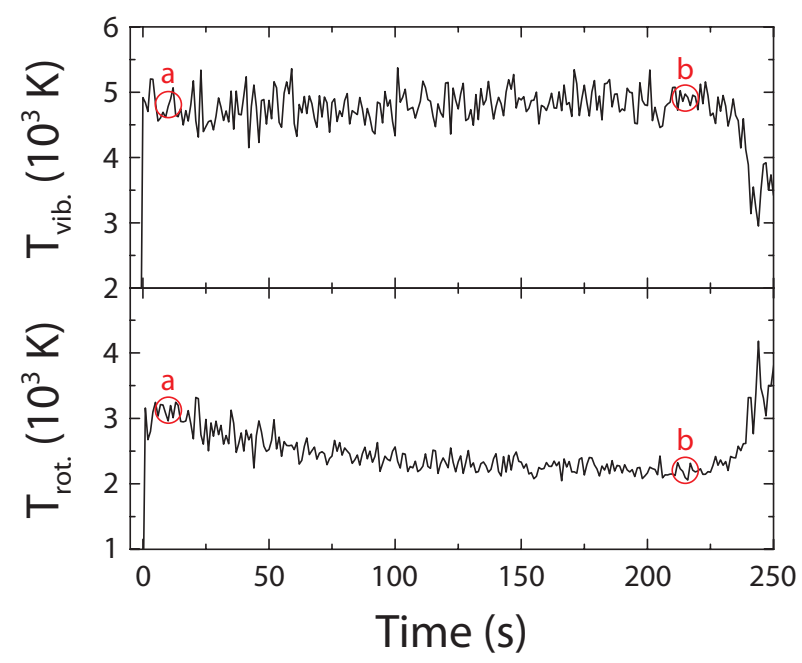

Figure 9: Rotational and vibrational temperature of $\mathrm{CH}(\mathrm{A}-\mathrm{X})$ during plasma erosion of an $a-\mathrm{C}: \mathrm{H}$ sample, corresponding to figure 7 . The measured spectra at points a and $\mathrm{b}$ (red circles) are shown in figure 10.

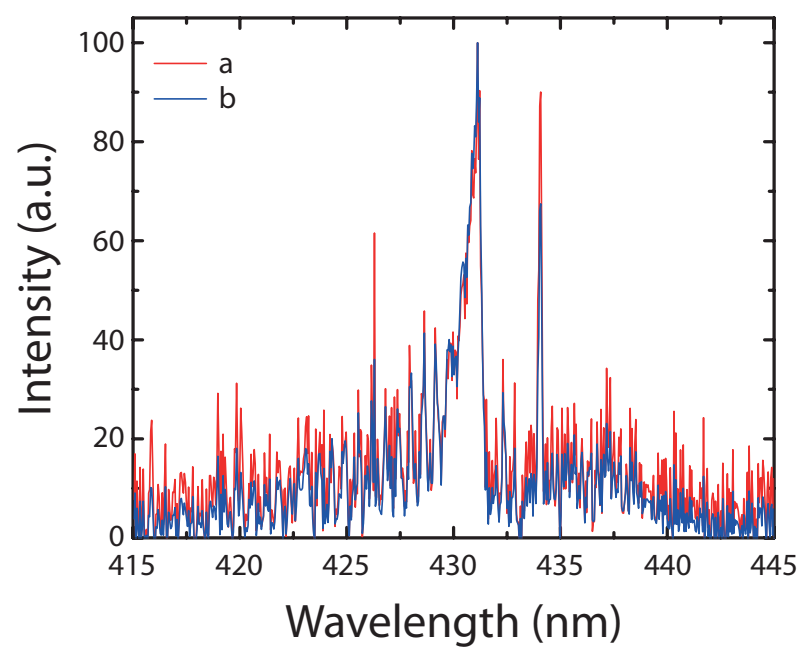

Figure 10: (Colour online) Average of the measured spectra from a) 5 to $14 \mathrm{~s}$ and b) 210 to $219 \mathrm{~s}$, corresponding to figure 9 . 


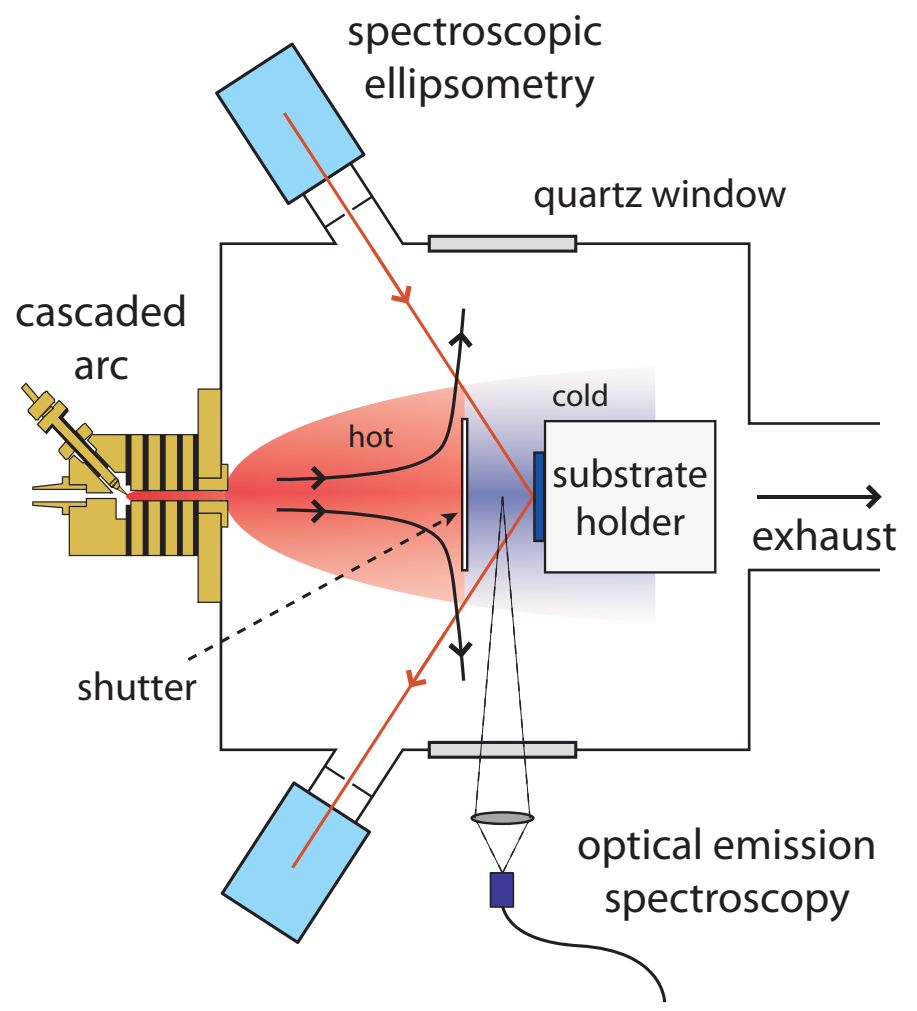

Figure 11: Schematic cross-section of the reactor with fixed arc and substrate. The plasma is deflected by the shutter towards the wall, effectively dividing the reactor into two. The focus of the optical system falls in between the shutter and the substrate.

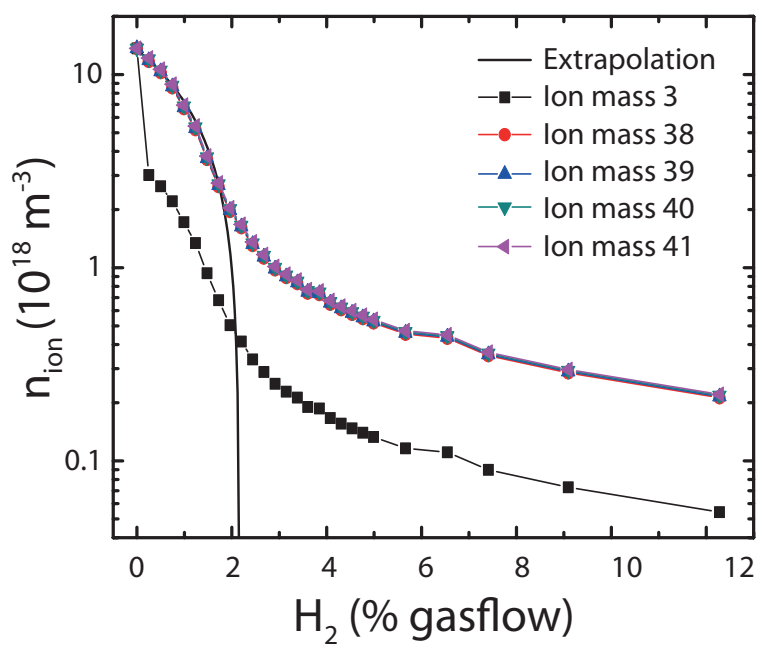

Figure 12: (Colour online) Ion density as function of the $\mathrm{H}_{2}$ gas flow. IV-characteristics measured with a double Langmuir probe are analysed for different ion masses to obtain the ion density. An ion mass of $40 \mathrm{amu}$ is used each time for a pure Ar plasma $\left(0 \% \mathrm{H}_{2}\right)$. The initial decline in ion density extrapolates to a $>100$-fold decrease at a gas flow of $\sim 2.2 \%$ when assuming a linear consumption of $\mathrm{Ar}^{+}$ions. The higher than expected ion density above this gas flow of $\sim 2.2 \%$ is attributed to $\mathrm{H}_{3}^{+}$formation, which counteracts the loss of $\mathrm{Ar}^{+}$in the total ion density. 


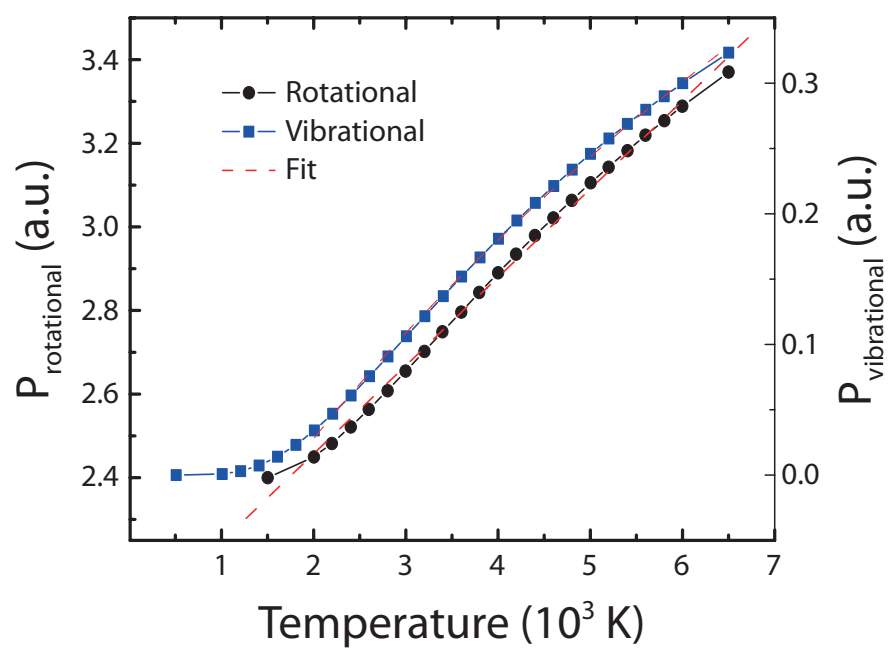

Figure 13: (Colour online) Proportionality factors for simulated rotational and vibrational temperatures of the $\mathrm{CH}(\mathrm{A}-\mathrm{X})$ emission band. The fit functions are given by equations $(2.2 a)$ and $(2.2 b)$. 
Table 1: Fit parameters for the equations $(2.2 a)$ to $(2.3 b)$.

\begin{tabular}{lcc}
\hline & $(2.2 a)$ & $(2.3 a)$ \\
\hline$a$ & $-5.28 \pm 0.57$ & $5729 \pm 640$ \\
$b$ & $0.600 \pm 0.06$ & $0.537 \pm 0.045$ \\
$c$ & $4959 \pm 816$ & $-4024 \pm 664$ \\
\hline$d$ & $(2.2 b)$ & $(2.3 b)$ \\
$e$ & $(2.10 \pm 0.03) \times 10^{-4}$ & $4737 \pm 63$ \\
\hline
\end{tabular}

